Bulletin of Pharmaceutical Sciences
Assiut University

\title{
ENHANCEMENT OF LIPOSOMAL DRUG LOADING BY USING SUPERSATURATED DRUG SOLUTION
}

\author{
Hassan Tamam ${ }^{1,2^{*}}$, Jelan A. Abdel-Aleem ${ }^{1}$, Sayed I. Abdelrahman ${ }^{1}$, Aly A. Abdelrahman ${ }^{1}$ \\ and Yoon $\mathrm{Yeo}^{2,3}$ \\ ${ }^{1}$ Department of Industrial Pharmacy, Faculty of Pharmacy, Assiut University, Assiut 71526, \\ Egypt \\ ${ }^{2}$ Department of Industrial and Physical Pharmacy, Purdue University, 575 Stadium Mall \\ Drive, West Lafayette, IN 47907, USA \\ ${ }^{3}$ Weldon School of Biomedical Engineering, Purdue University, West Lafayette, IN 47907, USA
}

\begin{abstract}
Liposomes are used for systemic delivery of chemotherapeutic drugs to reduce their nonspecific side effects. Liposomes can encapsulate hydrophilic and lipophilic drugs in the water compartment and the lipid membrane, respectively. However, typical drug loading capacity of liposomes by passive loading method is less than 1\%. The low drug loading efficiency is problematic because it necessitates the use of a large amount of carrier materials that may cause undesirable biological effects. To increase drug loading in liposomes, weusedsupersaturated drug solutionswith gemcitabine (GEM) and doxorubicin (Dox) as examples. The prepared liposomes showed higher drug loading compared with passive loading, maintainedstabilityand provided sustained drug release for 48 hrs.
\end{abstract}

\section{INTRODUCTION}

Liposomes are phospholipid bilayer vesicles with aqueous cores, discovered by $\mathrm{A}$. D. Bangham in $1960^{1}$. Within a few years, a variety of enclosed phospholipid bilayer structures consisting of single bilayers, initially termed 'bangosomes' and later'liposomes,' have been developed ${ }^{2}$. Gregory Gregoriadis et al..$^{3-5}$ have established the concept that liposomes could entrap drugs and serveas delivery system. It has been also shown that the liposomes could change the in vivo biodistribution of the entrapped drug ${ }^{6 \& 7}$. Many methods have been developed to produce large unilameller liposomes with improved entrapment efficacy and homogeneity ${ }^{8}$.

As a drug delivery system, liposomescanentrap both hydrophilic and hydrophobic compounds in the aqueous and lipid layer, respectively, and protect the entrapped drugs from decomposition, and help release the loaded drug at specific sites?

Received in 24/4/2019 \& Accepted in 5/5/2019

*Corresponding author: Hassan Tamam, E-mail: Hassantamam@aun.edu.eg
Liposomes have gained a lot of interest as a drug delivery system because of their biocompatibility, biodegradability, increased efficiency, therapeutic index, low toxicity ${ }^{10}$ and the potential for site-specific drug delivery to tumor tissues ${ }^{11}$.

Doxorubicin (Dox) and gemcitabine (Gem) havebeen tested clinically for treatment of various cancer types such as breast cancer $^{12 \& 13}$ and hepatocellular carcinoma ${ }^{14 \& 15}$. In addition, many studies tested the synergy between Dox and Gem in different types of cancer $^{16-21}$. The main mechanism of action of Dox is the intercalation with DNA and disruption of topoisomerase-II-mediated DNA repair and generation of free radicals and their damage to cellular membranes ${ }^{22}$. Gem, is a prodrug, which needs to be activated by phosphorylation to a triphosphate form of Gem $\left(2^{\prime}, 2^{\prime}\right.$-difluoro-2'-deoxycytidine triphosphate; $\mathrm{dFdCTP})^{23}$. dFdCTP is incorporated into the end of elongating DNA, followed by one more 
deoxynucleotide, whereoupon DNA polymerases stop proceeding ${ }^{24}$.

There is indeed need to produce liposomal Gem and Dox to increase the fraction of drug reaching tumor by EPR effect.

Low drug loading is problematic because it increases liposomal dose. Inefficient loading also increases the need for thorough removal of unentrapped drug $^{25}$. High drug loading is also needed for increasing the efficiency of chemotherapy as well as decreasing toxicity due to accumaltion of drugs in tumor in preference to other organs as reported by Mayer et $a .^{26}$. They have compared $\mathrm{LD}_{50}$ of liposomal Dox with different drug to lipid ratios (i.e., drug loading). The decrease of the drug to lipid ratio from $0.28: 1$ to $0.038: 1$ led to the decrease inLD ${ }_{50}$ from 57 to $39 \mathrm{mg} / \mathrm{kg}$ and increase inthe Dox accumulation in the heart by 1.8-fold. This increased toxicity results from the increase of drug leakage from the liposomes duringthe extended circulation.

In this study, we usedsupersaturated drug solutionto increase the entrapment of the drug in the aqueous phase of the liposomes, with Gem and Doxas model drugs, and evaluated the physicochemical properties of the prepared liposomes.

\section{MATERIALS AND METHODS}

\section{Materials}

Dipalmitoyl-sn-glycero-3-phosphocholine (DPPC), cholesterol,N-(carbonylmethoxypolyethylene-glycol-2000)-1, 2distearoyl-sn-glycero-3-phospho-ethanolamine (DSPE-PEG ${ }_{2000}$ ) and NBD-cholestrol were obtained from Avanti Polar Lipids (Alabaster, AL, USA). Gemcitabine and Doxorubicin HCL were purchased from LC laboratories Woburn, MA, USA. All other materials, including solvents, were purchased from Sigma Aldrich (St. Louis, MO, USA).

\section{Liposomes preparation}

Liposomes were prepared in the following procedures. A mixture of DPPC, cholesterol and DSPE-PEG ${ }_{2000}$ at a weight ratio of 6:3:1 (20 $\mathrm{mg}$ in total) was dissolved in $3 \mathrm{~mL}$ of mixture of chloroform and methanol (3:1 vol ratio). The organic solvent was removed using a rotary evaporator and thin lipid film was obtained. Sonicaton of hydrated film was performed using onic water bath for $15 \mathrm{~min}$ and extruded through polycarbonate membranes with a pore size of $400 \mathrm{~nm}$ and $200 \mathrm{~nm}$, sequentially, using a mini-extruder (Avanti polar lipid, Inc., AL.)

A thin lipid film was obtained by removing the solvents with a rotary evaporator at $45^{\circ} \mathrm{C}$ and hydrated according to the procedures detailed below. The hydrated lipid film was sonicated in a sonic water bath for 15 min and extruded through polycarbonate membranes with a pore size of $400 \mathrm{~nm}$ and 200 $\mathrm{nm}$, sequentially, using a mini-extruder. The drug-loaded liposomes were washed with deionized (DI) water 3 times by centrifugation using a Beckman Optima XL-I ultracentrifuge at 135,700 relative centrifugal force ( $\mathrm{rcf}$ ) at $4^{\circ} \mathrm{C}$.

Passive loading: The lipid film was hydrated with $1 \mathrm{~mL}$ of $5 \mathrm{mg} / \mathrm{mL}$ Gem or Dox solution and stirred in a rotary evaporator for $45 \mathrm{~min}$ at $45^{\circ} \mathrm{C}$, extruded and washed. The Gem-loaded liposomes prepared by this method is called $\mathrm{L}_{\mathrm{P}}$ Gand $\mathrm{L}_{\mathrm{P}} \mathrm{D}$.

Small volume loading (indirect loading with supersaturated drug solution) ${ }^{\mathbf{2 7}}$ : The formed thin lipid film was hydrated with $1.2 \mathrm{ml}$ of phosphate-buffered saline (PBS, $\mathrm{pH}$ 7.4). The hydrated film was bath sonicated for $10 \mathrm{~min}$, extruded and collected by centrifugation at 305, $400 \mathrm{rcf}$. The liposomal pellet was mixed with $0.1 \mathrm{~mL}$ of DI water containing $5 \mathrm{mg}$ of Gem (or Dox by vortexing which above the solubility limit 25 and $20 \mathrm{mg} / \mathrm{ml}$ for Gem and Dox respectively, and followed by overnight incubation at $60^{\circ} \mathrm{C}$. The prepared liposomes are called $\mathrm{L}_{\mathrm{S}} \mathrm{G}$ and $\mathrm{L}_{\mathrm{S}} \mathrm{D}$.

Preparation of labeled liposomes: Fluorescently labeled liposomes were prepared by the same method applied for small volume loading with replacement of cholesterol by 25 NBD-cholesterol and called L ${ }^{*}$ liposomes.

\section{Liposome characterization}

\section{Measuring the size and zeta potential}

The size-average (z-average) and zeta potential of each liposomal formulation were measured by a Malvern Zetasizer Nano ZS90, as dispersed in DI water (z-average) or in 1 $\mathrm{mM}$ phosphate buffer ( $\mathrm{pH}$ 7.4) (zeta potential). 
To estimate the loss of injection mass after injection, $1 \mathrm{~mL}$ of $\mathrm{L}_{\mathrm{p}} \mathrm{G}, \mathrm{L}_{\mathrm{p}} \mathrm{D}, \mathrm{L}_{\mathrm{s}} \mathrm{G}$ and $\mathrm{L}_{\mathrm{s}} \mathrm{D}$ suspension equivalent to $25 \mu \mathrm{g} / \mathrm{mL}$ Gem/Dox was passed through a $28 \mathrm{G}$ needle. The optical density of each suspension at $600 \mathrm{~nm}$ was measured before and after the passage by a SpectraMax M3 reader (Molecular Devices, CA, USA).

\section{TEM imaging of liposomes}

The liposomes were photographed by the Tecnai F20 transmission electron microscope (FEI, Hillsboro, OR, USA) after negative staining with $1 \%$ uranyl acetate.

\section{Drug loading efficiency}

The prepared liposomes were lyophilized, weighed, dispersed in $1 \mathrm{~mL}$ of acetonitrile to release the entrapped drug and bath-sonicated in cold water for $2 \mathrm{hrs}$. The liposomal suspension was diluted with an equal volume of DI water and centrifuged at $14000 \mathrm{rpm}$ for 20 min to obtain a clear supernatant. The supernatant was analyzed by high-pressure liquid chromatography (HPLC). HPLC analysis was performed by the Agilent 1100 system, (Agilent Technologies, Palo Alto, CA), equipped with a $\mathrm{C} 18$ column $(25 \mathrm{~cm} \times 4.6 \mathrm{~mm}$, particle size $5 \mu \mathrm{m}$ ) (Supelco, St. Louis, MO.). Gem was eluted with a 90:10 mixture of water and acetonitrile at a flow rate of $1 \mathrm{~mL} / \mathrm{min}$ and detected at $269 \mathrm{~nm}^{28}$. Dox was eluted with a 70:30 mixture of water and acetonitrile with $0.1 \%$ trifluoroacetic acid at a flow rate of 0.8 $\mathrm{mL} / \mathrm{min}$ and detected at $490 \mathrm{~nm}^{29}$. The drug loading efficiency $(\%)$ is defined as $\mathrm{W}_{\mathrm{D}} / \mathrm{W}_{\mathrm{L}} \times$ 100 , where $W_{D}$ is the amount of drug detected and $\mathrm{W}_{\mathrm{L}}$ the total amount of the liposomes analyzed.

\section{Stability of the liposomes}

The prepared liposomes are evaluated for their stability upon storage at $4^{\circ} \mathrm{C}$. Particle size, zeta potential and drug content weremonitored monthly for 3 months.

\section{In-vitro release}

Liposomes equivalent to $115 \mu \mathrm{g} / \mathrm{mL}$ of Gem and $250 \mu \mathrm{g} / \mathrm{mL}$ of Doxwere placed in a Float-A-Lyzer G2 dialysis device (Spectrum Laboratories, Inc., Rancho Dominguez, CA, USA) with a molecular weight cut-off of 100 $\mathrm{kDa}$. The device was incubated in $20 \mathrm{~mL}$ of
PBS (pH 7.4) at $37^{\circ} \mathrm{C}$ with constant agitation. At predetermined time points, $0.3 \mathrm{~mL}$ of the release medium was sampled and replaced with $0.3 \mathrm{~mL}$ of fresh buffer. The sampled buffer was filtered with a syringe filter $(0.45 \mu \mathrm{m}$ pore size) and analyzed for drug content by HPLC.

\section{Confocal imaging of labeled liposomes}

Huh7 cells were seeded in a $35 \mathrm{~mm}$ glassbottomed dish (Mat Tek Corp., Ashland, MA) at a density of 100,000 cells per dish. At 70\% confluence, the cells were treated with fluorescently labeled liposomes $\mathrm{L}^{*}$ for $1 \mathrm{~h}$. or 3 h. At each time point, the cells were rinsed twice with PBS. After nuclei staining with Hoechst $33342(5 \mu \mathrm{g} / \mathrm{mL})$ for $10 \mathrm{~min}$, the cells were rinsed again with PBS and imaged in medium by a Nikon-A1R confocal microscope (Nikon America Inc., Melville, NY).

\section{RESULTS AND DISCUSSION}

\section{Liposomal drug loading}

Liposomes prepared by passive loading (Gem for $\mathrm{L}_{\mathrm{P}} \mathrm{G}$ and Dox for $\mathrm{L}_{\mathrm{P}} \mathrm{D}$ ) showed a negligible drug loading of 0.14 and $0.5 \mathrm{wt} \%$, respectively. However, when loaded indirectly with supersaturated solutions of Gem and Dox, the drug loading of Gem and Dox increased to $3.8 \mathrm{wt}$ and $4.2 \%$ respectivelyas shown in table 1. The efficient drug loading by the latteris explained by the high concentration gradient between the external medium and the aqueous core. The supersaturated drug is provided from theoutside of the liposomes, keeping the concentration gradient across the membrane at the maximum throughout the loading process. The drug loading continues until the drug concentration gradient reaches zero ${ }^{30}$.

Table 1: Physical properties of prepared liposomes.

\begin{tabular}{||c|c|c|c||}
\hline Formula & $\begin{array}{c}\text { Passive } \\
\text { loading }\end{array}$ & $\begin{array}{c}\text { Small } \\
\text { volume } \\
\text { loading }\end{array}$ & $\begin{array}{c}\text { Loading } \\
\text { efficiency } \\
(\%)\end{array}$ \\
\hline LpG & + & & $0.14 \pm 0.05$ \\
\hline LpD & + & & $0.5 \pm 0.2$ \\
\hline $\mathrm{L}_{\mathrm{S}} \mathrm{G}$ & & + & $3.8 \pm 0.5$ \\
\hline $\mathrm{L}_{\mathrm{S}} \mathrm{D}$ & & + & $4.2 \pm 0.8$ \\
\hline
\end{tabular}

Data are presented as means \pm standard deviations of 3 tests of a representative batch. Drug loading efficiency: mass of loaded drug/mass of liposomes. 


\section{Particle size and Zeta potential}

The average size of liposomes measured by the DLS were $210-220 \mathrm{~nm}$ with an exception of $\mathrm{L}_{\text {blank }}$ which did not have any drug inside, the measured size was $142.2 \mathrm{~nm}$ (Table 2 ). The zeta potential was consistently negative irrespective of the loaded drug, due to the presence of cholesterol and DSPE-PEG $2000{ }^{31 \& 32}$. The optical density of $\mathrm{L}_{S} G$ orL $L_{S}$ Ddid not significantly change by needle passage, but that of $L_{p} G_{0} L_{p} D d i d$, suggesting the loss of liposomes (Table 3). This difference is due tolow loading in $\mathrm{L}_{\mathrm{p}} \mathrm{Gor}_{\mathrm{p}} \mathrm{D}$ which requires higher amount of liposomal nanoparticels to get the same drug concentration of of $L_{S} G$ or $\mathrm{L}_{S} \mathrm{D}$. The higher amount of nanoparticles increased the loss during needle passage.

Table 2: Particle size and zeta potential of prepared liposomes.

\begin{tabular}{|c|c|c|c|}
\hline Formula & $\begin{array}{c}\text { NP size } \\
(\mathrm{d}, \mathrm{nm})\end{array}$ & PDI & $\begin{array}{c}\text { Zeta } \\
\text { potential } \\
(\mathrm{mV})\end{array}$ \\
\hline LpG & $181 \pm 30$ & $0.10 \pm 0.1$ & $-29.7 \pm 6.4$ \\
\hline LpD & $200 \pm 10$ & $0.20 \pm 0.08$ & $-28.8 \pm 4.3$ \\
\hline LsG & $171 \pm 15$ & $0.08 \pm 0.02$ & $-28.2 \pm 5.5$ \\
\hline LsD & $188 \pm 9$ & $0.10 \pm 0.04$ & $-30.2 \pm 2.0$ \\
\hline L $_{\text {Blank }}$ & $142 \pm 9.4$ & $0.66 \pm 0.13$ & $-26.1 \pm 1.1$ \\
\hline
\end{tabular}

Table 3: \% Optical density after syringe transfer.

\begin{tabular}{|c|c|c|c|}
\hline LpG & LpD & LsG & LsD \\
\hline $90 \% \pm 0.5$ & $89 \% \pm 0.5$ & $95 \% \pm 1.0$ & $99 \% \pm 0.3$ \\
\hline
\end{tabular}

\section{In-vitro drug release}

$\mathrm{L}_{\mathrm{S}} \mathrm{D}$ and $\mathrm{L}_{\mathrm{S}} \mathrm{G}$ released $45 \%$ and $65 \%$ of the loaded drug over $48 \mathrm{hrs}$ for respectively. However, LpD and LpG showed burst release and released almost $100 \%$ of its content in 3 hrs. This burst release may be attributed to the presence of the drug in the hydrophobic lipid layer which is entrapped in liposomal membrane during preparation so it is released upon contact of release media. In contrast,with $L_{S} D$ and $L_{S} G$ the drug was entrapped in the aqueous core phasedue to passage of drug with the concentration gradient form high to low concetrationand faced the lipid bilayer which acts as diffusion barrier (Fig. 1).

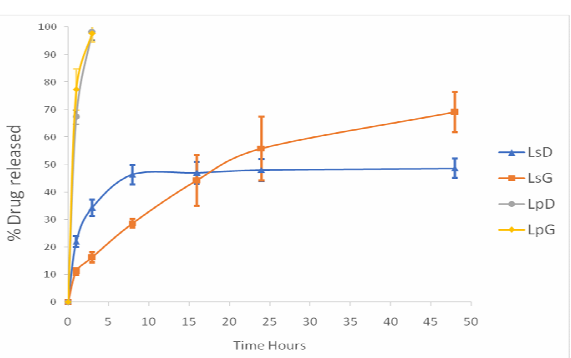

Fig. 1: In-vitro drug release of Dox and Gem from release $\mathrm{LpD}, \mathrm{LpG}, \mathrm{LsD}$ and $\mathrm{L}_{\mathrm{S}} \mathrm{G}$ at $\mathrm{pH}$ 7.4. $\mathrm{n}=3$ independent and identical batches. Mean \pm standard deviation (s.d.).

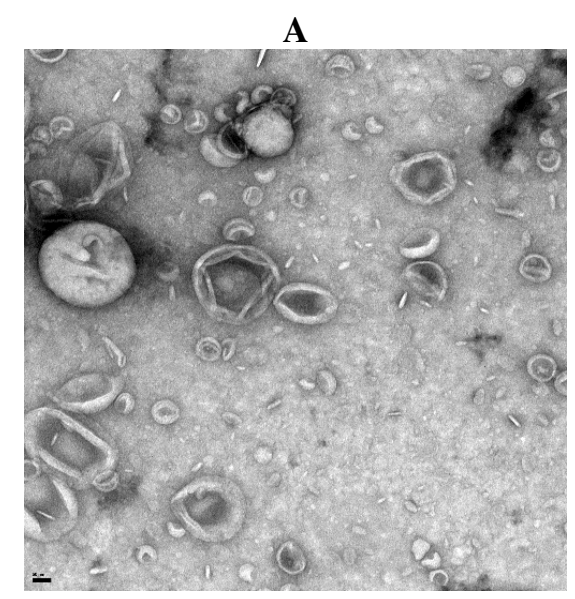

B

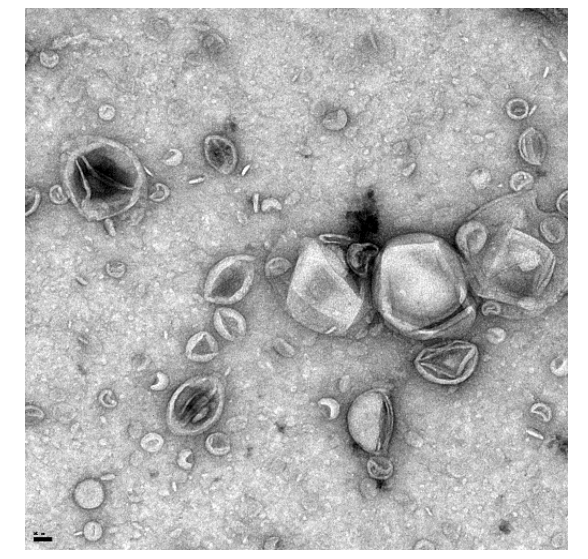

Fig. 2: TEM images of A) LsG and B) LsD. Scale bar: $50 \mathrm{~nm}$.

\section{Stability of liposomes}

The prepared liposomes showed good stability upon storage as indicated by insignificant change in particle size, zeta potential or drug content (Table 4). 
Cell ular uptake of liposomal drugs vs. free drug counterparts

Confocal microscope imagingclearly showed cellular uptake of the liposomes. Liposomal signals appeared near the nuclei and increased with time indicating that the liposomes were taken up and released their content inside the cells (Fig. 3).

Table 4: Stability of prepared liposomes.

\begin{tabular}{|c|c|c|c|c|c|c|}
\hline Formulation & $\begin{array}{l}\text { Storage } \\
\text { period } \\
\text { (Months) }\end{array}$ & $\begin{array}{l}\text { Initial size } \\
\quad(\mathrm{nm})\end{array}$ & $\begin{array}{c}\text { Initial Zeta } \\
\text { potential }\end{array}$ & $\begin{array}{l}\text { Size after } \\
\text { storage at } \\
4^{\circ} \mathrm{C}(\mathrm{nm})\end{array}$ & $\begin{array}{c}\text { Zeta } \\
\text { potential } \\
(\mathrm{mv})\end{array}$ & $\begin{array}{l}\% \text { Drug } \\
\text { Content }\end{array}$ \\
\hline \multirow{3}{*}{ LsG } & $\overline{1}$ & \multirow{3}{*}{$171 \pm 15$} & \multirow{3}{*}{$-28.2 \pm 5.5$} & $181 \pm 8$ & $-30.1 \pm 0.0$ & $99.8 \pm 3.0$ \\
\hline & 2 & & & $182 \pm 6$ & $-28.2 \pm 1.0$ & $98.5 \pm 2.0$ \\
\hline & 3 & & & $181 \pm 7$ & $-29.5 \pm 4.5$ & $99.0 \pm 1.0$ \\
\hline \multirow{3}{*}{ LsD } & 1 & \multirow{3}{*}{$188 \pm 9$} & \multirow{3}{*}{$-30.2 \pm 2.0$} & $223 \pm 2$ & $-29.8 \pm 1.5$ & $99.1 \pm 2.8$ \\
\hline & 2 & & & $208 \pm 6$ & $-28.6 \pm 2.0$ & $99.0 \pm 1.8$ \\
\hline & 3 & & & $235 \pm 1$ & $-29.0 \pm 1.5$ & $98.2 \pm 2.3$ \\
\hline
\end{tabular}

Data are presented as the averages \pm standard deviations of 3 independently and identically prepared batches.

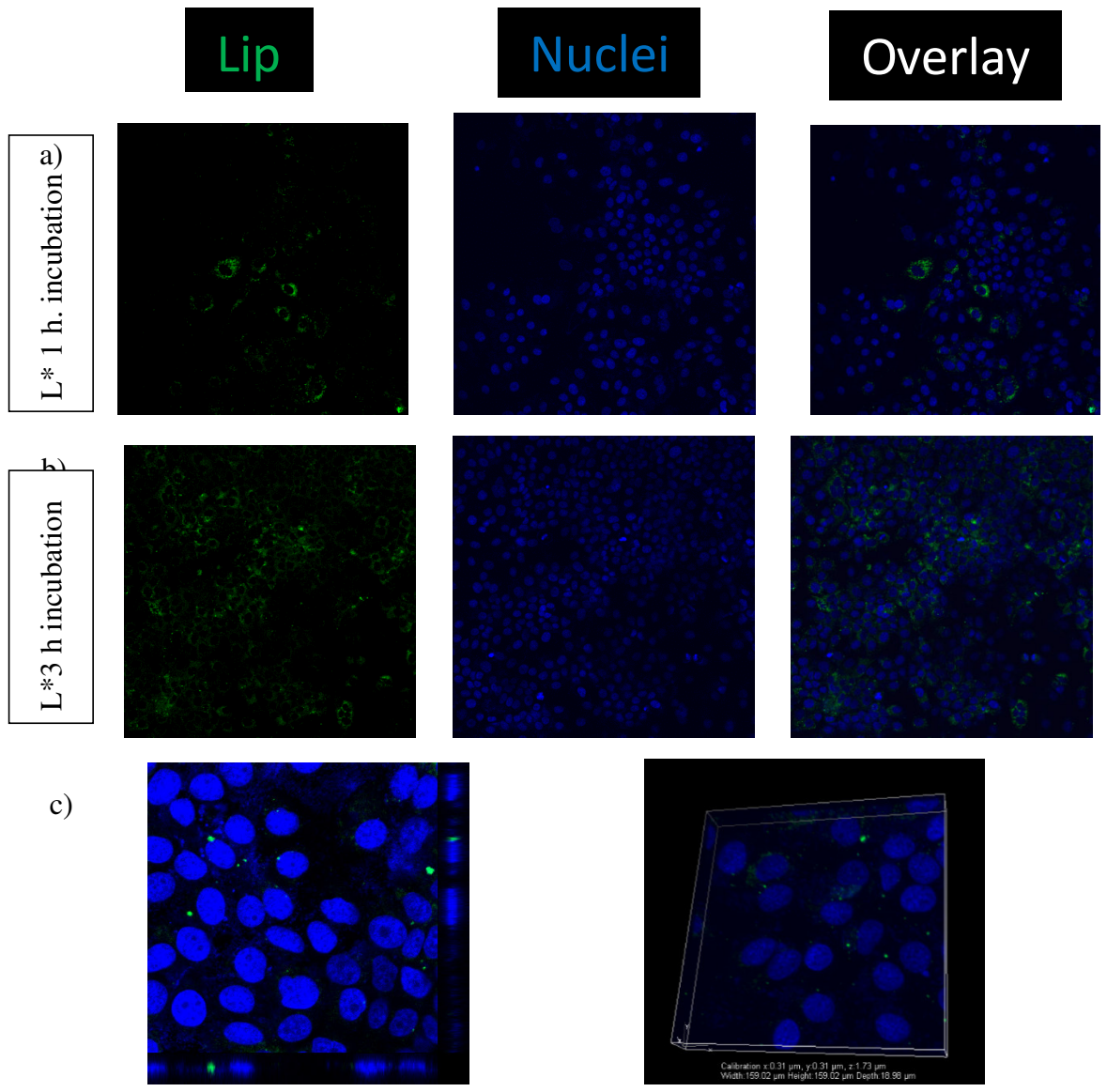

Fig. 3: Confocal microscopic images with 20x zoom of Huh7 cells incubated with 25-NBD cholesterol labeled $\mathrm{L}^{*}$ a) for $1 \mathrm{~h}$., b) for $3 \mathrm{hs}$ and c) Z-slice showing the liposomes beside the nuclei indicating that the liposomes were uptaken by the cells. Scale bars: $50 \mu \mathrm{m}$. 


\section{Conclusion}

The use of supersaturated drug solution helped increase drug loading compared with passive loading. The prepared liposomes showed sustained drug release for $48 \mathrm{hrs}$ and were stable on the shelf for 3 months. Confocal images showed that the liposomes were taken up by the cells and released its contents in the cells.

\section{REFERENCES}

1- A. D. Bangham and R. W. Horne, "Negative staining of phospholipids and their structural modification by surfaceactive agents as observed in the electron microscope", Journal of Molecular Biology, 8, 660-IN10 (1964).

2- D. W. Deamer, "From "Banghasomes" to liposomes: A memoir of Alec Bangham, 1921-2010", The FASEB Journal, 24, 1308-1310 (2010).

3- G. Gregoriadis and B. E Ryman, "Liposomes as carriers of enzymes or drugs: A new approach to the treatment of storage diseases", Vol. 124., 1971, P.58

4- G. Gregoriadis, "Drug entrapment in liposomes", FEBS Letters, 36, 292-296 (1973).

5- G. Gregoriadis, "The Carrier Potential of Liposomes in Biology and Medicine", Vol. 295, 1976, pp.765-70.

6- S. K. Alahari, R. DeLong, M. H. Fisher, N. M. Dean, P. Viliet and R. L. Juliano, "Novel Chemically Modified Oligonucleotides Provide Potent Inhibition of P-Glycoprotein Expression", Journal of Pharmacology and Experimental Therapeutics, 286, 419-428 (1998).

7- H. K. Kimelberg, T. F. Tracy, S. M. Biddlecome and R. S. Bourke, "The effect of entrapment in liposomes on the in-vivo distribution of methotrexate in a primate", Cancer Research, 36, 2949-2957 (1976).

8- F. Szoka and D. Papahadjopoulos, "Procedure for preparation of liposomes with large internal aqueous space and high capture by reverse-phase evaporation", Proceedings of the National Academy of Sciences, 75, 4194-4198 (1978).
9- T. Shehata, K.-i. Ogawara, K. Higaki and T. Kimura, "Prolongation of residence time of liposome by surface-modification with mixture of hydrophilic polymers", International Journal of Pharmaceutics, 359, 272-279 (2008).

10- M. J. W. Johnston, S. C. Semple, S. K. Klimuk, S. Ansell, N. Maurer and P. R. Cullis, "Characterization of the drug retention and pharmacokinetic properties of liposomal nanoparticles containing dihydrosphingomyelin", Biochimica. et Biophysica. Acta. (BBA) Biomembranes, 1768, 1121-1127 (2007).

11- R.-D. Hofheinz, S. Ulrike Gnad-Vogt, U. Beyer and A. Hochhaus, Liposomal Encapsulated Anti-Cancer Drugs, 16, 691-707 (2005).

12- E. Rivera, V. Valero, B. Arun, M. Royce, R. Adinin, K. Hoelzer, R. Walters, J. L. Wade, L. Pusztai and G. N. Hortobagyi, "Phase II study of pegylated liposomal doxorubicin in combination with gemcitabine in patients with metastatic breast cancer", Journal of Clinical Oncology, 21, 3249-3254 (2003).

13- G. Pérez-Manga, A. Lluch, E. Alba, J. A. Moreno-Nogueira, M. Palomero, J. García-Conde, D. Khayat and N. Rivelles, "Gemcitabine in combination with doxorubicin in advanced breast cancer: final results of a phase ii pharmacokinetic trial", ibid., 18, 2545-2552 (2000).

14- T. S. Yang, "Gemcitabine and doxorubicin for the treatment of patients with advanced hepatocellular carcinoma: A phase I-II trial", Annals of Oncology, 13, 1771-1778 (2002).

15- G. Lombardi, F. Zustovich, F. Farinati, U. Cillo, A. Vitale, G. Zanus, M. Donach, M. Farina, S. Zovato and D. Pastorelli, "Pegylated liposomal doxorubicin and gemcitabine in patients with advanced hepatocellular carcinoma: Results of a phase 2 study", Cancer, 117, 125-33 (2011).

16- R. Nahire, M. K. Haldar, S. Paul, A. H. Ambre, V. Meghnani, B. Layek, K. S. Katti, K. N. Gange, J. Singh, K. Sarkar and S. Mallik, "Multifunctional polymersomes for cytosolic delivery of gemcitabine and doxorubicin to cancer cells", Biomaterials, 35, 6482-6497 (2014). 
17- T. Anajafi, M. D. Scott, S. You, X. Yang, Y. Choi, S. Y. Qian and S. Mallik, "Acridine orange conjugated polymersomes for simultaneous nuclear delivery of gemcitabine and doxorubicin to pancreatic cancer cells", Bioconjugate Chemistry, 27, 762-771 (2016).

18- D. R. Vogus, M. A. Evans, A. Pusuluri, A. Barajas, M. Zhang, V. Krishnan, M. Nowak, S. Menegatti, M. E. Helgeson, T. M. Squires and S. Mitragotri, "A hyaluronic acid conjugate engineered to synergistically and sequentially deliver gemcitabine and doxorubicin to treat triple negative breast cancer", J. Control. Release, 267, 191-202.

19- D. R. Vogus, A. Pusuluri, R. Chen and S. Mitragotri, "Schedule dependent synergy of gemcitabine and doxorubicin: Improvement of in-vitro efficacy and lack of in-vitro - in-vivo correlation", Bioeng. Transl. Med., 3, 49-57 (2018).

20- T. Lammers, V. Subr, K. Ulbrich, P. Peschke, P. E. Huber, W. E. Hennink and G. Storm, "Simultaneous delivery of doxorubicin and gemcitabine to tumors invivo using prototypic polymeric drug carriers", Biomaterials, 30, 3466-75 (2009).

21- D. Liu, Y. Chen, X. Feng, M. Deng, G. Xie, J. Wang, L. Zhang, Q. Liu and P. Yuan, "Micellar nanoparticles loaded with gemcitabine and doxorubicin showed synergistic effect", Colloids Surf. B. Biointerfaces, 113, 158-68 (2014).

22- D. Gewirtz, "A critical evaluation of the mechanisms of action proposed for the antitumor effects of the anthracycline antibiotics adriamycin and daunorubicin", Biochemical Pharmacology, 57, 727-741 (1999).

23- L. de Sousa Cavalcante and G. Monteiro, "Gemcitabine: Metabolism and molecular mechanisms of action, sensitivity and chemoresistance in pancreatic cancer", Eur. J. Pharmacol., 741, 8-16 (2014).

24- V. Gandhi, J. Legha, F. Chen, L. W. Hertel and W. Plunkett, "Excision of 2',2'difluorodeoxycytidine (gemcitabine) monophosphate residues from DNA", Cancer Res., 56, 4453-4459 (1996).
25- Y. Barenholz, "Doxil ${ }^{(\mathrm{R})}$-the first FDAapproved nano-drug: Lessons learned", $\boldsymbol{J}$. Control. Release, 160, 117-34 (2012).

26- L. D. Mayer, L. C. L. Tai, D. S. C. Ko, D. Masin, R. S. Ginsberg, P. R. Cullis and M. B. Bally, "Influence of vesicle size, lipid composition, and drug-to-lipid ratio on the biological activity of liposomal doxorubicin in mice", Cancer Res., 49, 5922 (1989).

27- S. Modi, T. X. Xiang and B. D. Anderson, "Enhanced active liposomal loading of a poorly soluble ionizable drug using supersaturated drug solutions", J. Control. Release, 162, 330-9 (2012).

28- Y. Liu, H. Tamam and Y. Yeo, "Mixed liposome approach for ratiometric and sequential delivery of paclitaxel and gemcitabine", AAPS Pharm. Sci. Tech., (2017).

29- S. Dreis, F. Rothweiler, M. Michaelis, J. Cinatl, Jr. J. Kreuter and K. Langer, "Preparation, characterisation and maintenance of drug efficacy of doxorubicin-loaded human serum albumin (HSA) nanoparticles", Int. J. Pharm., 341, 207-14 (2007).

30- H. Xu, J. Paxton, J. Lim, Y. Li, W. Zhang, L. Duxfield and Z. Wu, "Development of high-content gemcitabine PEGylated liposomes and their cytotoxicity on drugresistant pancreatic tumour cells", Pharm. Res., 31, 2583-92 (2014).

31- A. Magarkar, V. Dhawan, P. Kallinteri, T. Viitala, M. Elmowafy, T. Rog and A. Bunker, "Cholesterol level affects surface charge of lipid membranes in saline solution", Sci. Rep., 4, 5005 (2014).

32- G. N. C. Chiu, M. B. Bally and L. D. Mayer, "Effects of phosphatidylserine on membrane incorporation and surface protection properties of exchangeable poly(ethylene glycol)-conjugated lipids", Biochimica. et Biophysica. Acta. (BBA) Biomembranes, 1560, 37-50 (2002). 
Bull. Pharm. Sci., Assiut University, Vol. 42, 2019, pp. 31-38.

نشرة العلوم الصيدليـة

\section{تحسين معلل تحميل الدوائي للليبوزومات عن طريق استخذام سوائل دو ائية مشبعة}

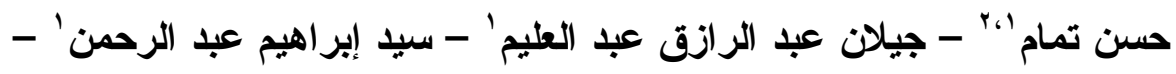

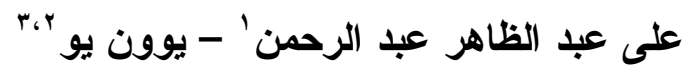

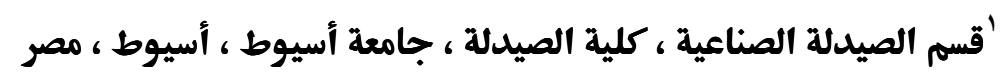

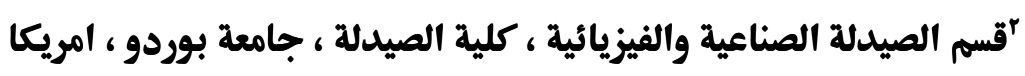

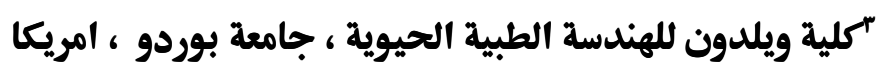

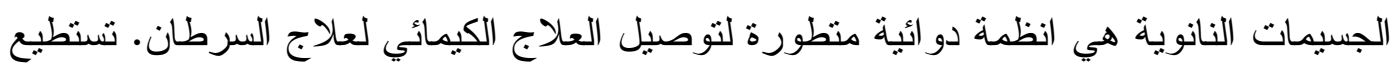

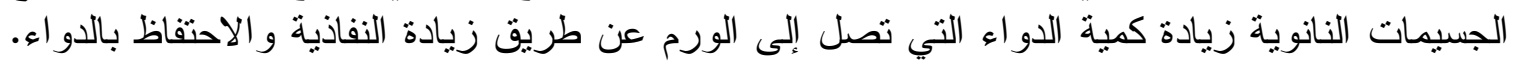

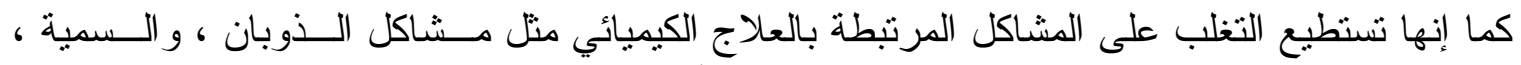

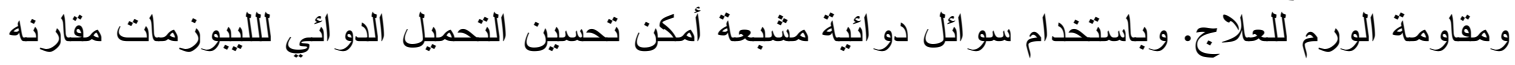

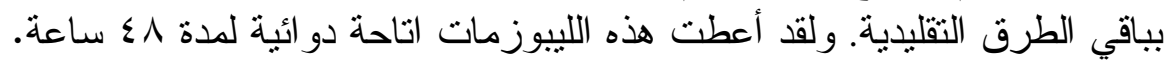

